\title{
NECROTISING FASCIITIS: A CLINICOPATHOLOGICAL STUDY
}

\author{
Ajitha M. B', Sonia Rani P. B2
}

${ }^{1}$ Associate Professor, Department of General Surgery, Bangalore Medical College and Research Institute, Bangalore. ${ }^{2}$ Postgraduate, Department of General Surgery, Bangalore Medical College and Research Institute, Bangalore.

ABSTRACT

\section{BACKGROUND}

Necrotising Fasciitis (NF) is a necrotising soft tissue infection involving the fascia and subcutaneous tissue. It can cause rapid local tissue necrosis and life-threatening severe sepsis that needs prompt recognition, extensive debridement, immediate antibiotic therapy and intensive care treatment.

The aim of this study was to investigate the aetiopathogenesis, demographics, different sites of involvement, investigations and management of necrotising fasciitis.

\section{METHODS AND MATERIALS}

The study was undertaken from July 2015 to June 2016 for a period of one year, patients who were admitted to surgical department at Bangalore Medical College and Research Institute formed the study.

\section{RESULTS}

50 patients of necrotising fasciitis were treated during the study period. The age group ranged from 21-90 years. There were 39 males and 11 females. The lower extremity was the most common site involved in $28(56 \%)$ patients followed by the perineum in $12(24 \%)$ patients and upper extremity in 5(10\%) patients. We witnessed one case of necrotising infection of the breast. No predisposing factor was present in $27(54 \%)$ patients. Trivial trauma was the most common predisposing factor found in 18 (36\%) patients. Regarding clinical features, local erythema and swelling were present in 38 (76\%) patients, pain was present in 31 (62\%) patients, bullous lesion was present in 15 (30\%) patients. The commonest organism involved was E. coli in 13 (26\%) patients followed by Klebsiella found in $9(18 \%)$ patients. Accurate assessment and timely intervention are critical in the treatment of patients affected with NF. Understanding the history and unique characteristics of this disease is crucial to achieve early recognition, effective treatment and a favourable outcome.

\section{CONCLUSION}

Necrotising fasciitis is a life threatening infection of the fascia and subcutaneous tissue. The presentation of the disease is nonspecific and variable. High index of suspicion and knowledge is essential for early diagnosis of NF. Delay in recognition and effective treatment increases the mortality. Radical surgical debridement, broad spectrum antibiotics, negative pressure wound dressings, and hyperbaric oxygen therapy are considered to be the cornerstone of treatment.

\section{KEYWORDS}

Necrotising Fasciitis, Debridement, Hyperbaric Oxygen.

HOW TO CITE THIS ARTICLE: Ajitha MB, Rani SPB. Necrotising fasciitis: A clinicopathological study. J. Evolution Med. Dent. Sci. 2016; 5(80):6001-6004, DOI: 10.14260/Jemds/2016/1354

\section{BACKGROUND}

Necrotising fasciitis is characterised by widespread necrosis of the subcutaneous tissue and fascia. It affects mainly the abdominal wall, perineum and extremities, though uncommonly it can occur anywhere on the body and rarely affects the breast.[1]

Mortality remains still high in NF despite use of modern powerful antimicrobial drug regimens and advances in the care of the critically ill patients. Mortality rate has been reported to vary from $4.2 \%$ to $75 \% .{ }^{[2-5]}$ Early diagnosis with aggressive multidisciplinary treatment is mandatory.

Financial or Other, Competing Interest: None.

Submission 26-08-2016, Peer Review 22-09-2016,

Acceptance 28-09-2016, Published 06-10-2016.

Corresponding Author:

Dr. Sonia Rani P. B,

\#319, Vishranthi Dhama,

Victoria Hospital Campus,

Bangalore- 560002.

E-mail: soniarani911@gmail.com

DOI: $10.14260 /$ jemds $/ 2016 / 1354$
Necrotising soft tissue infection (NSTI) is a rapidly progressing inflammatory infection of the fascia with the secondary involvement of skin, subcutaneous tissue and muscle.[6] It needs prolonged intensive care treatment due to accompanied systemic inflammatory response syndrome (SIRS).[7]

In order to find out the aetiopathogenesis, demographics, different sites of involvement, morbidity and mortality and management of necrotising soft tissue infection, a prospective study was conducted in the Department of General Surgery at Bangalore Medical College and Research Institute, Bangalore for a period of one year.

\section{MATERIALS AND METHODS}

The study was undertaken from July 2015 to June 2016 for a period of one year, patients who were admitted to our teaching hospital formed part of the study. Data collected for each patient included age, sex, associated comorbidities, site of involvement, predisposing factors, clinical and laboratory parameters, bacteriology, secondary surgical procedures and final outcome. The diagnosis of necrotising fasciitis was based 
on clinical findings, presence of dull grey, necrotic superficial fascia and subcutaneous tissues with serosanguinous fluid and microscopic demonstration of extensive polymorphonuclear cell infiltration in the dermis and underlying fascia with obliterative thrombosis of arteries and veins. The patients initially received intravenous fluids and antibiotics, aggressive surgical debridement. Definitive wound coverage was performed after the patients were free of infection and when the wound became healthy.

\section{Exclusion Criteria}

Patients with associated comorbidities like diabetes mellitus, liver cirrhosis, chronic heart failure, immunodeficiency, preexisting hypertension, and peripheral vascular disease.

\begin{tabular}{|c|c|c|}
\hline $\begin{array}{c}\text { Age } \\
\text { Group }\end{array}$ & $\begin{array}{c}\text { Total No. } \\
\text { of Cases }\end{array}$ & $\begin{array}{c}\text { Percentage } \\
\text { (\%) }\end{array}$ \\
\hline $21-30$ & 2 & 4 \\
\hline $31-40$ & 3 & 6 \\
\hline $41-50$ & 7 & 14 \\
\hline $51-60$ & 17 & 34 \\
\hline $61-70$ & 15 & 30 \\
\hline $71-80$ & 4 & 8 \\
\hline $81-90$ & 2 & 4 \\
\hline \multicolumn{2}{|r|}{ Table 1: Age wise distribution of Patients } \\
\hline
\end{tabular}

\begin{tabular}{|c|c|c|}
\hline Sites & Cases & Percentage (\%) \\
\hline Lower extremity & 28 & 56 \\
\hline Fournier's gangrene & 12 & 24 \\
\hline Upper extremity & 5 & 10 \\
\hline Abdominal wall & 2 & 4 \\
\hline Perianal region & 2 & 4 \\
\hline Breast & 1 & 2 \\
\hline \multicolumn{3}{|c|}{$\begin{array}{c}\text { Table 2: Distribution of Cases according to sites } \\
\text { involved in Necrotising Fasciitis }\end{array}$} \\
\hline
\end{tabular}

\section{PERCENTAGE OF INVOLVEMENT OF DIFFERENT SITES}

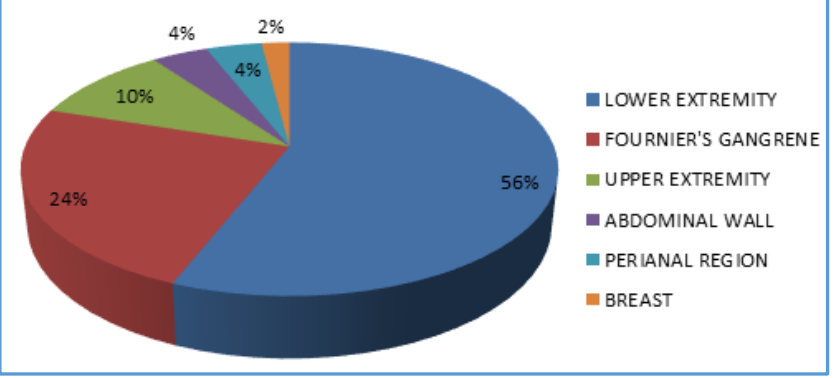

Table 3 reveals that the commonest organism involved was E. coli in 13 (26\%) patients followed by Klebsiella found in $9(18 \%)$ patients. In laboratory tests of patients, 39 patients had leucocytosis. 23 patients had an increase in the level of serum creatinine $(>1.5 \mathrm{mg} / \mathrm{dL})$. Extensive surgical debridement was done for 47 cases. Nine cases died which included seven cases of lower extremity, one with upper extremity and one with breast involvement.

Thorough surgical debridement and secondary suturing was done in nine cases, out of which seven patients with Fournier's gangrene and two with abdominal wall involvement. Split skin grafting was done in 26 patients, which included five patients of Fournier's gangrene, 18 of lower extremity and three of upper extremity involvement. Four patients underwent amputation, of which three were aboveknee amputation and one was above-elbow amputation.

One patient with perianal necrotising infection with loss of anal sphincter tone underwent sphincter tone reconstruction using gracilis muscle sphincteroplasty and a diverting colostomy. The temporary diverting colostomy helped in the healing of skin grafts. Patient was advised for perineal exercise. On regular followup after 2 months, anal sphincter tone improved.

\begin{tabular}{|c|c|c|}
\hline Organism & No & \% \\
\hline E. coli & 13 & 26 \\
\hline Klebsiella & 9 & 18 \\
\hline Streptococcus & 8 & 16 \\
\hline Pseudomonas & 6 & 12 \\
\hline Staphylococcus & 5 & 10 \\
\hline Acinetobacter & 4 & 8 \\
\hline Proteus & 3 & 6 \\
\hline Enterococcus & 2 & 4 \\
\hline \multicolumn{2}{|c|}{ Table 3: Commonly Identified Organisms } \\
\hline
\end{tabular}

\section{DISCUSSION}

In 1952, Wilson coined the term "necrotising fasciitis," to describe the dominant feature of the disease, namely inflammation and necrosis of the subcutaneous fat and the deep fascia with sparing of muscle. [8] Historically, necrotising infections were classified according to anatomical sites. Fournier's gangrene (involving the perineum) and Ludwig angina (involving submandibular and sublingual spaces) and Meleney's synergistic gangrene (involving abdominal wall) are examples. These infections were named after the physicians who first described them.

\section{Pathogenesis}

An accurate predictor of the disease has not been consistently demonstrated. The inoculation of the bacteria into the subcutaneous space can occur with any damage to the overlying skin or via haematogenous spread from a distant site. Reported mechanism of injury has included cuts, burns, blunt and penetrating trauma, chronic skin conditions, animal and insect bites, intravenous injections and illegal drugs, postoperative infection and perirectal abscesses.[9-11] In up to $36 \%$ of cases; however, no preceding skin lesions or antecedent injury can be found.[11]

\section{Risk Factors}

- Age greater than 50 years.

- Atherosclerosis.

- Burns.

- Immunocompromised state.

- Chronic alcoholism.

- Corticosteroid use.

- Diabetes mellitus.

- Hypoalbuminaemia.

- Intravenous drug abuse.

- Malnutrition.

- Obesity.

- Peripheral vascular disease.

- Postoperative infection.

- Trauma. 


\section{Microbiology}

In a study by Elliott et al[12], it was found that the majority of monomicrobial infections were caused by streptococcal species like beta-haemolytic streptococci (namely, Group A streptococci or Streptococcus pyogenes). Other common monomicrobial necrotising soft tissue infections include Staphylococcus aureus and Clostridium perfringens.

The organisms most common in polymicrobial necrotising soft tissue infections are combinations of staphylococci (Staphylococcus epidermidis with beta-haemolytic streptococci), enterococci, Enterobacteriaceae species (commonly Escherichia coli, Proteus mirabilis, Klebsiella pneumoniae, and Pseudomonas aeruginosa), streptococci, Bacteroides/Prevotella species, anaerobic Gram-positive cocci, and Clostridium species.[13]

\section{Diagnosis}

The diagnosis of NF is mainly clinical and should be suspected when the skin appears red or darkened, tender or swollen, with formation of bluish bullae and the local picture is associated with fever and severe pain disproportionate to the obvious physical signs.[14]

\section{CLINICAL FINDINGS IN NECROTISING FASCIITIS Early Findings \\ - Pain. \\ - Cellulitis. \\ - Pyrexia. \\ - Tachycardia. \\ - Swelling. \\ - Induration. \\ - Skin anaesthesia.}

\section{Late Findings}

- Severe pain.

- Skin discoloration (purple or black).

- Blistering.

- Haemorrhagic bullae.

- Crepitus.

- Discharge of "dishwater" fluid.

- Severe sepsis or systemic inflammatory response syndrome.

- Multiorgan failure.

However, clinical suspicion may not be enough because these equivocal signs may initially mimic simple cellulitis, or mastitis, delaying diagnosis; the use of imaging, (Ultrasound, MRI or CT scan) may help in this context because findings such as irregularity of the fascia, abnormal fluid collections or gas tracking along fascial planes, fat stranding and diffuse thickening of the fascia outline the presence of necrosis that demands aggressive surgical management.[14-16]

Blood tests also proved useful, and Wong proposed the use of the 'Laboratory Risk Indicator for Necrotising Fasciitis' score may help in suspicious cases as a score of 6-7 should indicate early imaging or surgical exploration to rule out NF.[14]

Ultrasound findings correlate reasonably well with histological fat changes in NF, but poor correlation with fascial and muscle abnormalities. It is helpful in differentiating Fournier's gangrene from an acute scrotum.[17] CT scanning has been demonstrated to show asymmetric fascial thickening, fat stranding and soft tissue gas, which aid in diagnosis of NF. It can also provide information about co-existent deep collection and it is helpful in determining the extent of spread of infection.[18] Magnetic resonance imaging with gadolinium can differentiate necrotic and inflamed or oedematous tissue. T2 weighted images on MRI with fat suppression are probably the best radiological adjunctive investigation to demonstrate deep fascial involvement and is more sensitive than specific.[19]

\section{Management}

The key aspects of management include early diagnosis, resuscitation of the patient, administration of broad spectrum antibiotics followed by radical surgical debridement, intensive care support and finally, reconstruction of the resulting wound. $[2-5,7]$

\section{Surgery}

Emergency surgical debridement of the affected tissues is the primary management modality for NF. Surgical debridement, necrosectomy, and fasciotomy are the main aspects of surgical treatment. Surgical intervention is life-saving and must be performed as early as possible, since a delay in treatment beyond 12 hours in fulminant forms of NF can prove fatal. Many studies have pointed out that timing and the extent of the first debridement are the most important risk factors in terms of increased mortality rate. Mock et al have shown that the relative risk of death was 7.5 times greater in cases of restricted primary debridement[20], whereas other studies reported that the mortality rate was nine times greater when primary surgery was performed 24 hours after the onset of symptoms.[21]

Surgery also minimises the overall tissue loss as it inhibits infection spread to the fascial plane reducing the need for amputation.[22] Re-exploration and further debridement are often required to achieve control of the necrotising process. Surgical wounds must be frequently re-evaluated for evidence of disease extension. In perineal NF, diverting colostomy and/or urinary diversion are often needed to control infection. Amputation of extremities is sometimes necessary, particularly in patients with diabetes and/or peripheral vascular disease. Reconstructive procedures including skin grafting, flap or free flap are often required.

\section{Antibiotics \\ Parenteral antimicrobial therapy must assure broad coverage for a wide range of pathogens including aerobic Gram-positive, Gram-negative organisms and anaerobes. The main goal of antibiotic therapy is infection control, avoiding haematogenous dissemination, while waiting surgical intervention. A beta-lactam/beta-lactamase combination such as ampicillin/sulbactam, piperacillin/tazobactam or ticarcillin/clavulanate are reasonable empiric choices. For penicillin-allergic patients, clindamycin and aztreonam association is an acceptable alternative. Third or fourth- generation cephalosporins with metronidazole or clindamycin for anaerobic coverage are also recommended.}

\section{Supportive Care}

Evidence of haemodynamic instability demands immediate resuscitation, transfer to an intensive care unit, nutritional support, and enteral feeding. 


\section{Adjuvant Therapy}

Hyperbaric Oxygen therapy is widely used in the treatment of acute and chronic infections because of numerous profitable actions: direct antimicrobial effect, increase in antibiotic drug efficacy, reduction of oedema, enhanced angiogenesis and fibroblasts proliferation. These benefits impact positively on all the phases in the treatment of $\mathrm{NF}$, synergistically improving both infection control and wound healing.[23]

The mortality rates for NF vary considerably with the best centres claiming less than $10 \%$ and others as high as $75 \% .{ }^{[2-}$ 5,7] The larger, more comprehensive retrospective studies have narrowed these rates between $25 \%$ and $40 \%$. The outcome is also region- specific with truncal (44\%) and perineal (28\%) having higher mortality than extremities $(22 \%)$, presumably due to the option of amputation of the limb in the event of an extensive infection. ${ }^{21,22]}$

\section{CONCLUSION}

Necrotising fasciitis is a rare but life-threatening condition, with a high mortality rate. Establishing the diagnosis of NSTI is one of the biggest challenges in treating patients with NSTI. Accuracy increases with familiarity of clinical findings and knowledge of laboratory, imaging, and macroscopic and microscopic findings, all combined with a high index of suspicion. Since delay in recognition and effective treatment increases the mortality of NF, early diagnosis and management of NF are essential for a better outcome.

All patients should be treated promptly with appropriate antibiotics, which are tailored to the nature of the infecting organism.

Radical surgical debridement, along with second surgeries when needed, is the definitive management and is also frequently diagnostic in patients who have not presented with classical dermatological signs. The role of HBO therapy and intravenous immunotherapy has been reported to be beneficial and would require further study.

\section{REFERENCES}

1. Green RJ, Dafoe DC, Raffin TA. Necrotizing fasciitis. Chest 1996;110(1):219-29.

2. De Tullio D, Rossi C, Bolzon S, et al. Necrotizing fasciitis: a surgical emergency. Updates Surg 2010;62(2):83-7.

3. Carter PS, Banwell PE. Necrotizing fasciitis: a new management algorithm based on clinical classification. Internat Wound J 2004;1(3):189-98.

4. Shimizu T, Tokuda Y. Necrotizing fasciitis. Inter Med 2010;49(12):1051-7.

5. Descamps V, Aitken J, Lee MG. Hippocrates on necrotising fasciitis. Lancet 1994;344(8921):556.

6. Morgan MS. Diagnosis and management of necrotising fasciitis: a multiparametric approach. J Hosp Infect 2010;75(4):249-57.
7. Levine EG, Manders SM. Life-threatening necrotizing fasciitis. Clin Dermatol 2005;23(2):144-7.

8. Wilson B. Necrotizing fasciitis. Am Surg 1952;18(4):41631.

9. Childers BJ, Potyndy LD, Nachreiner R, et al. Necrotizing fasciitis: a fourteen-year retrospective study of 163 consecutive patients. Am J Surg 2002;68(2):109-16.

10. Elliott DC, Kufera JA, Myers RA. Necrotizing soft tissue infections. Risk factors for mortality and strategies for management. Ann Surg 1996;224(5):672-83.

11. Aronoff DM, Bloch KC. Assessing the relationship between the use of nonsteroidal anti-inflammatory drugs and necrotizing fasciitis caused by group A streptococcus. Medicine 2003;82(4):225-35.

12. Elliott D, Kufera JA, Myers RA. The microbiology of necrotizing soft tissue infections. American Journal of Surgery 2000;179(5):361-6.

13. Chapnick EK, Abter EI. Necrotizing soft-tissue infections. Infectious Disease Clinics of North America 1996;10(4):835-55.

14. Puvanendran R, Huey JC, Pasupathy S. Necrotizing fasciitis. Can Fam Physician 2009;55(10):981-7.

15. Brothers TE, Tagge DU, Stutley JE, et al. Magnetic resonance imaging differentiates between necrotizing and non-necrotizing fasciitis of the lower extremity. J Am Coll Surg 1998;187(4):416-21.

16. Tsai CC, Lai CS, Yu ML, et al. Early diagnosis of necrotizing fasciitis by utilization of ultrasonography. Kaohsiung J Med Sci 1996;12(4):235-40.

17. Begley MG, Shawker TH, Robertson CN, et al. Fournier gangrene: diagnosis with scrotal ultrasound. Radiology 1988;169(2):387-9.

18. Wysoki MG, Santora TA, Shah RM, et al. Necrotizing fasciitis: CT characteristics. Radiology 1997;203(3):85963.

19. Arslan A, Pierre-Jerome C, Borthne A. Necrotizing fasciitis: unreliable MRI findings in the preoperative diagnosis. Eur J Radiol 2000;36(3):139-43.

20. Mok MY, Wong SY, Chan TM, et al. Necrotizing fasciitis in rheumatic diseases. Lupus 2006;15(6):380-3.

21. Roje Z, Roje Z, Matic D, et al. Necrotizing fasciitis: literature review of contemporary strategies for diagnosing and management with three case reports: torso, abdominal wall, upper and lower limbs. Word J Emerg Surg 2011;6(1):46.

22. Wang KC, Shih CH. Necrotizing fasciitis of the extremities. J Trauma 1992;32(2):179-82.

23. Bhutani S, Vishwanath G. Hyperbaric oxygen and wound healing. Indian J Plast Surg 2012;45(2):316-24. 